\title{
Identifikasi Sifat Asam Basa Menggunakan Indikator Alami Bunga Karamunting (Rhodomyrtus tomentosa)
}

\author{
Media Br. Karo \\ SMA Negeri 3 Bulik, Kabupaten Lamandau, Kalimantan Tengah, Indonesia
}

\begin{abstract}
Abstrak. Selain kandungan antioksidan pada buah, daun Karamunting mengandung senyawa golongan flavonoid, steroid, triterpenoid, tanin galat, tanin katekekat, kuinon dan unsur natrium, kalsium, kalium serta magnesium. Tujuan penelitian ini adalah untuk mengetahui apakah bunga karamunting dapat di gunakan sebagai indikator alami untuk menentukan sifat asam basa suatu larutan. Metode penelitian 1) Menyiapkan bunga karamunting. 2) Membuat ekstrak bunga karamunting. Pada pembuatan indickator alami, bunga di cuci dengan air mengalir agar bersih juga dimaksudkan agar pigmen warna bunga tidak ikut larut dalam air. Bunga yang sudah di cuci di haluskan kemudian di saring. 3) Meneteskan ekstrak bunga karamunting pada Larutan cuka, Air jeruk nipis, air Kapur, dan air sabun. 4) Mengamati dan mencatat perubahan yang terjadi. Hasil penelitian menunjukkan estrak bunga karamunting dapat dijadikan indikator alami untuk menentukan sifat asam dan basa suatu zat atau senyawa karena memberikan perubahan warna yang jelas pada asam dan basa. Pada larutan asam menjadi merah muda dan pada larutan basa menjadi coklat.
\end{abstract}

Kata Kunci: asam basa, indikator, karamunting

\section{PENDAHULUAN}

Air murni adalah air yang tidak mempunyai rasa, bau, dan warna, dan air murni termasuk larutan bersifat netral. Dalam kehidupan sehari-hari kita tidak hanya mengenal larutan yang bersifat netral, tetapi juga larutan yang bersifat asam dan basa. Sejak dahulu orang sudah mencoba untuk mengidentifikasi sifat larutan ini dengan berbagai indikator khusus.

Asam dalam bahasa Inggris acid dan dalam bahasa Latin acidus yang berarti rasa asam. Secara kimia asam adalah zat yang dalam air dapat menghasilkan ion Hidrogen $\left(\mathrm{H}^{+}\right)$. Asam akan terionisasi menjadi ion Hidrogen dan ion sisa asam yang bermuatan negatif. Sifat-sifat asam adalah sebagai berikut:

- Mempunyai rasa masam.

- Mengubah lakmus biru menjadi merah.

- Bersifat korosif. Oleh karnanya asam dapat melarutkan berbagai jenis logam, semisal seng, dan aluminium.

- Mempunyai pH yang kurang dari 7.

Basa adalah suatu senyawa yang jika dilarutkan dalam air dapat melepaskan ion hidroksida $\left(\mathrm{OH}^{-}\right)$. Sifat-sifat basa yaitu:

- Mempunyai rasa pahit

- Dapat mengubah lakmus merah menjadi biru.

- Dapat menetralkan asam.

- Basa kuat bersifat kaustik. Apabila terkena kulit (seperti Natrium Hidroksida) akan terasa perih dan menyebabkan luka.

- Mempunyai pH lebih dari 7.

Setiap zat atau senyawa mempunyai sifat asam, basa atau netral. Untuk mengetahui sifat asam, basa, atau netral dapat dengan menggunakan suatu Indikator. 
Indikator adalah zat yang dapat digunakan untuk menunjukan sifat suatu zat melalui perubahan warnanya yang khas. Indikator ini dapat berupa Indikator buatan yang ada di Laboratorium, atau juga dapat menggunakan indikator asam-basa dengan menggunakan bahan dari alam.

Indikator buatan yaitu indikator siap pakai yang sudah dibuat dilaboratorium atau pabrik alat-alat kimia. Contohnya adalah kertas lakmus dan indikator universal.

Identifikasi sifat asam dan basa dengan menggunakan kertas Lakmus di ciptakan oleh para Ilmuwan dari sejenis zat yang diperoleh dari jenis Lumut kerak/Liken (Rocella tinctoria), suatu jenis simbiosis jamur dan alga. Lakmus yang banyak digunakan dalam Laboratorium- laboratorium kimia sekarang ini tersedia dalam bentuk kertas. Kertas lakmus jenisnya ada dua, yaitu kertas Lakmus merah dan kertas Lakmus biru.

Semua zat tergolong asam apabila:

- $\quad$ Lakmus Biru berubah menjadi merah, atau

- $\quad$ Lakmus merah tidak berubah warna

Semua zat tergolong basa apabila:

- $\quad$ Lakmus merah berubah menjadi biru, atau

- Lakmus biru tidak berubah warna

Indikator universal merupakan campuran dari bermacam-macam indikator yang dapat menunjukkan $\mathrm{pH}$ suatu larutan dari perubahan warnanya. Indikator universal ada dua macam yaitu indikator yang berupa kertas dan larutan.

a. Indikator Kertas (Indikator Stik)

Indikator kertas berupa kertas serap dan tiap kotak kemasan indikator jenis ini dilengkapi dengan peta warna. Penggunaannya sangat sederhana, sehelai indikator dicelupkan ke dalam larutan yang akan diukur pH-nya. Kemudian dibandingkan dengan peta warna yang tersedia.
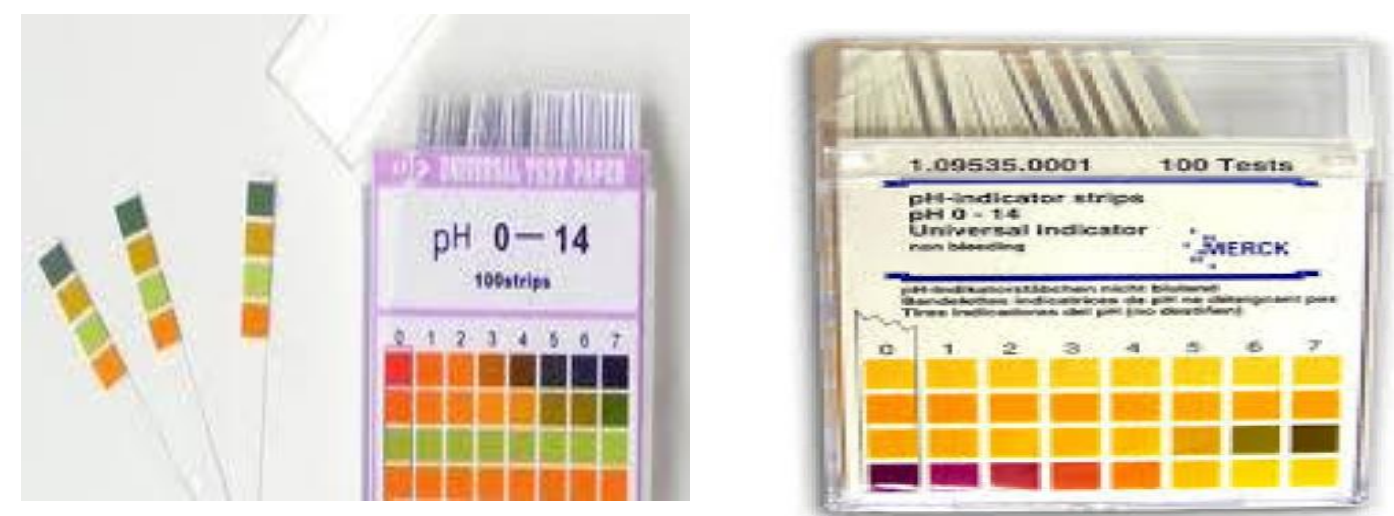

Gambar 1. Indikator Universal Kertas (Indikator Stik)

\section{b. Larutan Indikator}

Identifikasi sifat asam basa dengan menggunakan larutan Indikator universal yang ada dilaboratorium menggunakan empat jenis larutan yaitu larutan fenolftalein, metil merah, metil jingga, dan bromtimol biru.

Metil jingga adalah indikator $\mathrm{pH}$ yang sering digunakan dalam titrasi karena perubahan warnanya yang jelas dan kontras. Oleh karena ia berubah warna pada $\mathrm{pH}$ sedikit asam, maka biasa digunakan dalam titrasi asam. Tidak seperti indikator 
universal, metil jingga tidak memiliki spektrum perubahan warna yang lengkap, tetapi memiliki titik akhir yang lebih tajam.

Fenolftalein, adalah salah satu indikator asam basa sintentik yang memiliki rentang $\mathrm{pH}$ antara 8,00-10,0. jika pada larutan asam tidak memiliki warna. Pada larutan Basa berwarna merah. Dan pada larutan netral tidak memiliki warna.

Metil merah, sama dengan larutan metil jingga. jika pada larutan asam berwarna merah, pada larutan basa berwarna kuning. Dan pada larutan netral berwarna kuning.

Bromtimol biru jika pada larutan asam berwarna kuning, pada larutan basa berwarna biru, dan jika pada larutan netral berwarna biru agak kuning.

Untuk mengidentifikasi sifat asam basa larutan, selain menggunakan kertas lakmus dan indikator universal, kita juga dapat menggunakan indikator alami yaitu yang berasal dari tumbuh-tumbuhan.

Indikator alami adalah indikator yang berasal dari bahan - bahan alami, dimana cara memperolehnya yaitu dengan cara mengekstrak. Prinsip indikator adalah bahan yang memberikan warna berbeda pada zat yang bersifat asam dan basa. Indikator alami yang biasa di pakai dalam pengujian asam-basa adalah tumbuhan yang berwarna mencolok, umbi-umbian, kulit buah, berupa bunga - bungaan, seperti bunga sepatu, bunga hidrangea, kol ungu, kunyit, kembang kertas, dan beberapa jenis tumbuhan lainnya. Indikator asam-basa yang baik adalah zat warna yag memberi warna berbeda dalam larutan asam dan larutan basa.

Dengan didasari pemikiran bahwa zat warna pada tanaman merupakan senyawa organik bewarna seperti dimiliki oleh indikator sintetis, selain itu mudah dibuat juga murah karena bahan-bahannya mudah didapat. Pada percobaan ini kami menggunakan indikator alami dari ekstrak bunga karamunting. Karamunting (Rhodomyrtus tomentosa atau Ochthocharis Bornensis BI), merupakan tanaman liar berkayu yang termasuk kedalam famili Myrtaceae (jambu-jambuan). Karamunting mempunyai nama yang berbeda dibeberapa daerah antara Kalamunting (Pekanbaru), Haramonting (Sumatra Utara), dan Harendong Sabrang (Jawa Barat).

Tanaman ini berasal dari Asia Selatan dan Asia Tenggara dan akhirnya menyebar kedaerah tropis dan subtropis sampai ketinggian $2400 \mathrm{~m}$. Karamunting dapat tumbuh pada berbagai habitat dan jenis tanah. Di beberapa tempat tanaman ini digunakan sebagai tanaman hias, mengingat warna bunganya yang sangat menarik. Tetapi ditempat lain, tanaman ini dianggap sebagai gulma (tanaman pengganggu) karena pertumbuhannya yang sangat cepat sehingga mengalahkan vegetasi aslinya. Karamunting mempunyai pertumbuhan yang cepat dan dapat mencapai ketinggian 4-12 m. Letak daun berlawanan, daun berbentuk oval, bagian atas daun berwarna hijau mengkilap, bagian bawah daun berwarna abu-abu berbulu. Panjang daun $5-7 \mathrm{~cm}$ dan lebar 2-3 cm. Bunga tunggal atau berkelompok (klaster) 2-3 bunga, diameter 2,5-3 cm dengan warna beragam dari merah muda (pink) sampai ungu dengan benang sari banyak dan tidak beraroma.

Tumbuhan karamunting (Rhodomyrtus tomentosa (Aiton)Hassk) adalah tumbuhan liar pada tempat yang mendapat sinar matahari yang cukup, seperti di lereng gunung, lapangan yang tidak terlalu gersang. Ciri-ciri tumbuhan ini termasuk dalam kelompok perdu, daun tunggal, pangkal daun membulat, tepi daun rata, ujung daun meruncing.

\section{- Morfologi tumbuhan}


Tumbuhan Karamunting adalah termasuk jenis famili Myrtaceae(Suku jambujambuan). Karamunting adalah sejenis tanaman liar dengan pohon berkayu. Di padangpadang terbuka tingggi hampir setinggi orang dewasa (tingginya dapat 4 meter). Daunnya keras, panjang $5-7 \mathrm{~cm}$, dan luasnya $2-3,5 \mathrm{~cm}$, oval, ujungnya dari tumpul sampai dengan tajam, di atas hijau mengkilap, di bawah lebih abu-abu. Bungannya tesembunyi atau dalam dua atau tiga kelompok. Buahnya dapat dimakan, panjang 10$15 \mathrm{~mm}$, berwarna ungu hitam

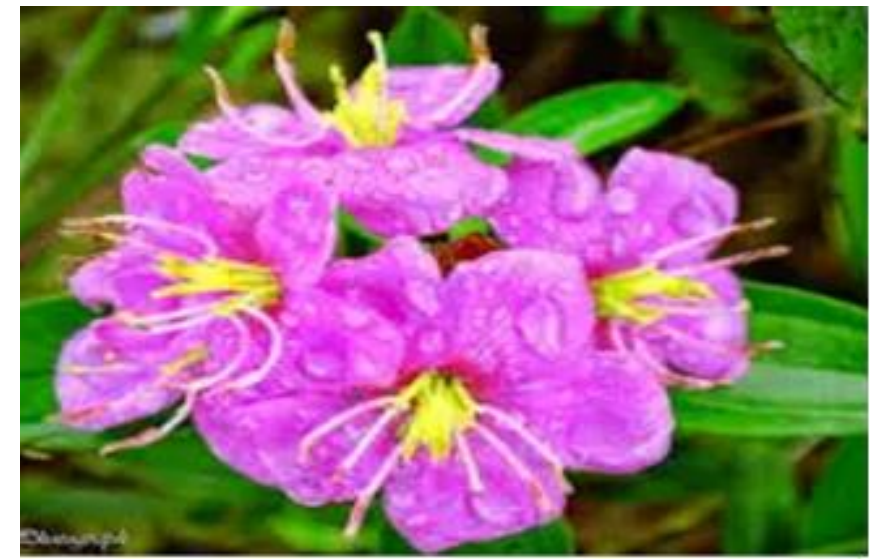

Gambar 2. Bunga Karamunting

\section{- Identifikasi tumbuhan}

Berdasarkan hasil identifikasi sampel tumbuhan Karamunting yang dilakukan di Herbarium Bogoriense Bidang Botani Pusat Penelitian Biologi Lembaga Ilmu Pengetahuan Indonesia(LIPI) Bogor, diperoleh klarifikasi tumbuhan sebagai berikut:

Nama daerah : Karamunting

Kingdom : Plantae

Divison : Magnolophyta

Kelas : Magnoliopsida

Ordo : Myrtales

Genus : Rhodomyrtus

Famili : Myrtaceae

Spesies $\quad$ : Rhodomyrtus tomentosa(Aiton) Hassk.

- $\quad$ Kandungan Buah Karamunting

Buah Karamunting (Rhodomyrtus Tomentosa (Aiton) Hassk) mengandung tanin, flavonoid dan karetinoid(Ngoc,dkk,2013)

Buah karamunting (Rhodomyrtus Tomentosa (Aiton) Hassk) megandung senyawa Flavonoid.<smiles>O=c1c(O)c(-c2ccc(O)c(O)c2)oc2cc(O)ccc12</smiles>

Gambar 3. Struktur Falvonoid 


\section{- $\quad$ Kegunaan tumbuhan Karamunting}

Salah satu tumbuhan yang digunakan sebagai tumbuhan obat adalah tumbuhan Karamunting. Bagian yang digunakan sebagai obat adalah daun yang berfungsi sebagai obat diare. Buahnya digunakan sebagai antibiotik dan obat diare. Sari akarnya digunakan untuk mengobati sakit jantung, mengurangi rasa sakit setelah melahirkan, obat diare, dinfeksi kulit, dan untuk perawatan bekas luka pada kornea mata (Ngoc,dkk,2013). Buah Karamunting digunakan juga sebagai pewarna tas naken di wilayah Papua dan untuk mewarnai Ulos Batak.

Selain kandungan antioksidan pada buah, daun Karamunting mengandung senyawa golongan flavonoid, steroid, triterpenoid, tanin galat, tanin katekekat, kuinon dan unsur natrium, kalsium, kalium serta magnesium.

Tujuan penelitian ini adalah untuk mengetahui apakah bunga karamunting dapat di gunakan sebagai indikator alami untuk menentukan sifat asam basa suatu larutan. Penelitian ini dibatasi pada bunga karamunting yang diteliti sebagai indikator alami untuk menentukan sifat asam basa suatu larutan.

\section{METODE PENELITIAN}

Metode penelitian ini adalah experimental dengan menggunakan ekstrak bunga karamunting dan di laksanakan pada tanggal 30 Nopember 2016 bertempat di SMA Negeri 3 Bulik kabupaten Lamandau. Subjek penelitian ini adalah ekstrak bunga karamunting yang digunakan sebagai indikator alami untuk mengidentifikasi sifat asam dan basa suatu zat atau senyawa.

Alat dan Bahan yang digunakan yaitu:

- Cuka

- $\quad$ Air jeruk nipis

- $\quad$ Air kapur sirih $\left(\mathrm{Ca}(\mathrm{OH})_{2}\right)$

- $\quad$ Air suling

- Air Sabun

- Bunga Karamunting

- Gelas ukur

- $\quad$ Air Bersih

- Sendok

Langkah-langkah penelitian yaitu:

a. Menyiapkan bunga karamunting.

b. Membuat ekstrak bunga karamunting. Pada pembuatan indickator alami, bunga di cuci dengan air mengalir agar bersih juga dimaksudkan agar pigmen warna bunga tidak ikut larut dalam air. Bunga yang sudah di cuci di haluskan kemudian di saring.

c. Meneteskan ekstrak bunga karamunting pada Larutan cuka, Air jeruk nipis, air Kapur, dan air sabun

d. Mengamati dan mencatat perubahan yang terjadi. 


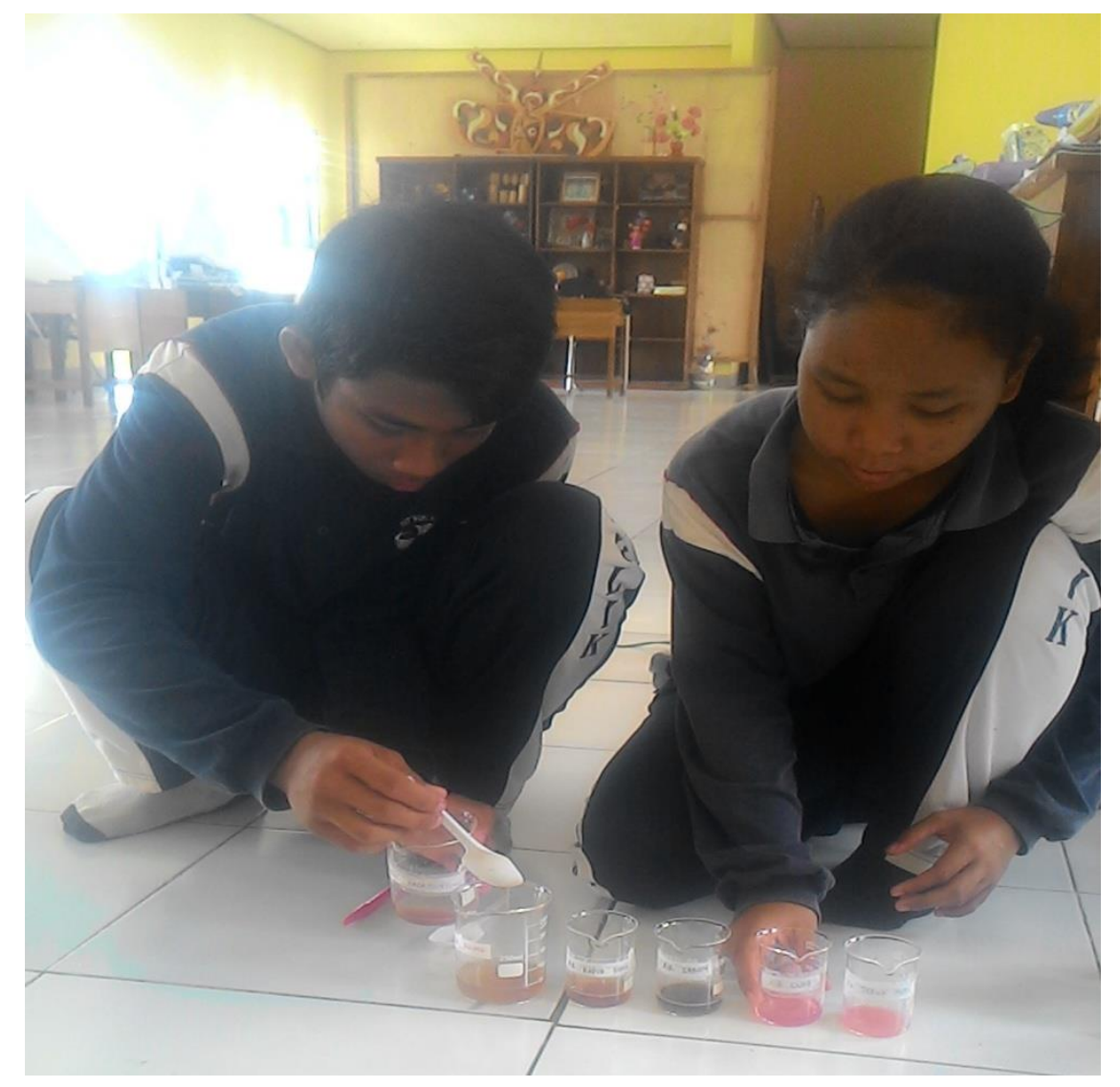

Gambar 4. Pada Saat Melakukan Penelitian

\section{HASIL PENELITIAN DAN PEMBAHASAN}

\section{Hasil Penelitian}

Berdasarkan penelitian yang telah dilakukan, maka di hasilkan data sebagai berikut:

\begin{tabular}{|c|c|c|c|c|c|}
\hline No & Indikator Alam & $\begin{array}{l}\text { Larutan yang } \\
\text { di uji }\end{array}$ & $\begin{array}{c}\text { Sebelum di } \\
\text { tetesi } \\
\text { ekstrak }\end{array}$ & $\begin{array}{c}\text { Sesudah di } \\
\text { tetesi } \\
\text { ekstrak }\end{array}$ & $\begin{array}{c}\text { Perubahan } \\
\text { warna }\end{array}$ \\
\hline 1 & & $\begin{array}{l}\text { Cuka } \\
\left(\mathrm{CH}_{3} \mathrm{COOH}\right)\end{array}$ & Bening & $\begin{array}{l}\text { Merah } \\
\text { muda }\end{array}$ & $\begin{array}{lr}\text { Dari } & \text { bening } \\
\text { menjadi } & \text { merah } \\
\text { muda } & \end{array}$ \\
\hline 3 & Bunga & Air Jeruk & Putih keruh & $\begin{array}{l}\text { Merah } \\
\text { muda }\end{array}$ & $\begin{array}{l}\text { Dari putih keruh } \\
\text { menjadi merah } \\
\text { muda }\end{array}$ \\
\hline 4 & & Air Sabun & Putih keruh & Coklat & $\begin{array}{l}\text { Dari putih keruh } \\
\text { menjadi coklat }\end{array}$ \\
\hline 5 & & $\begin{array}{l}\text { Kapur } \\
\left(\mathrm{Ca}(\mathrm{OH})_{2}\right)\end{array}$ & Bening & Coklat & $\begin{array}{l}\text { Dari bening } \\
\text { menjadi coklat }\end{array}$ \\
\hline
\end{tabular}

\section{Pembahasan}

Dari hasil penelitian dapat di amati perubahan warna pada larutan cuka dan air jeruk nipis mengalami perubahan warna dari semula bening dan setelah di tetes (atau di 
tuang menggunakan sendok) ekstrak bunga karamunting, berubah menjadi merah muda.

Pada air sabun dan Air kapur mengalami perubahan warna dari semula bening dan putih keruh dan setelah ditetes (atau di tuang menggunakan sendok) berubah menjadi coklat

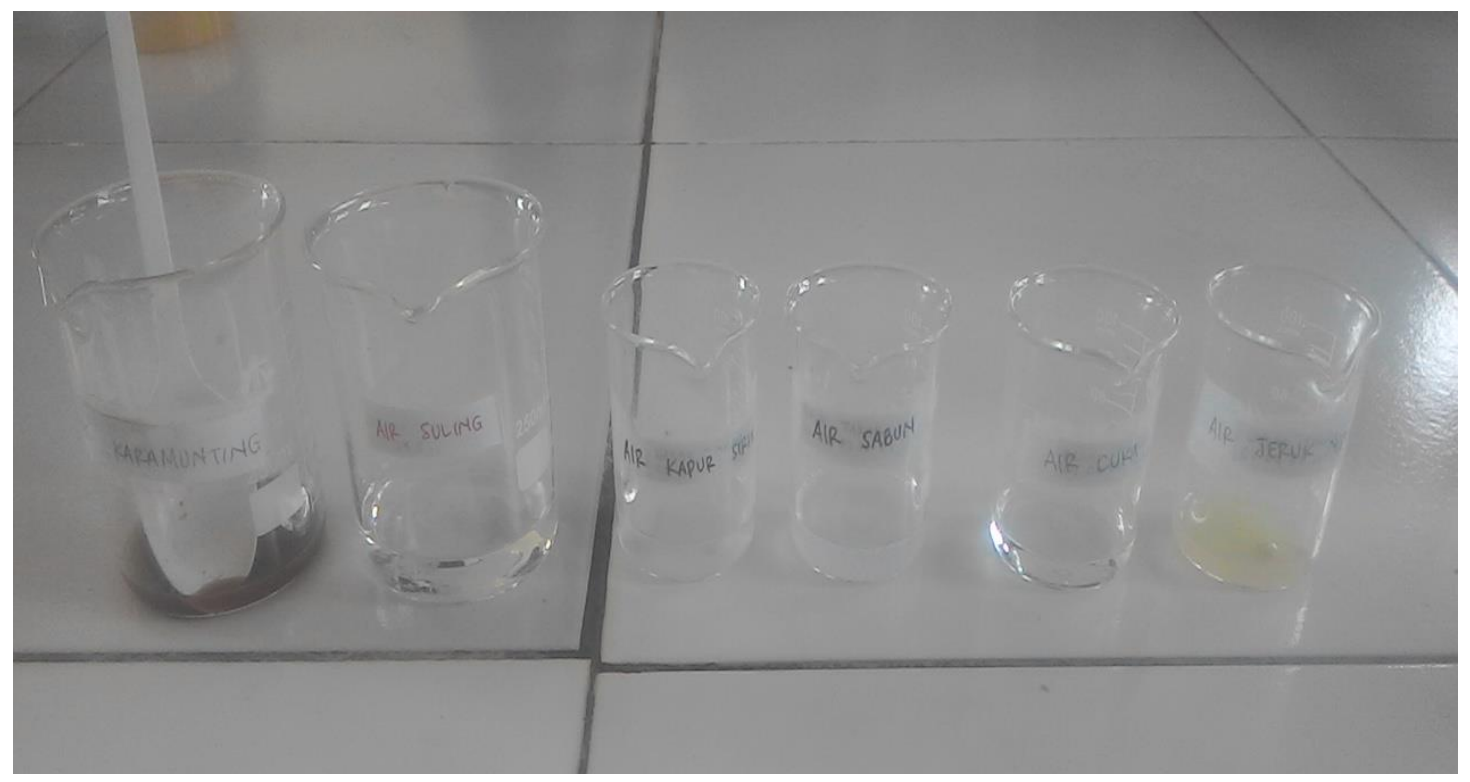

Gambar 5. Sebelum di tetesi ekstrak Bunga Karamunting

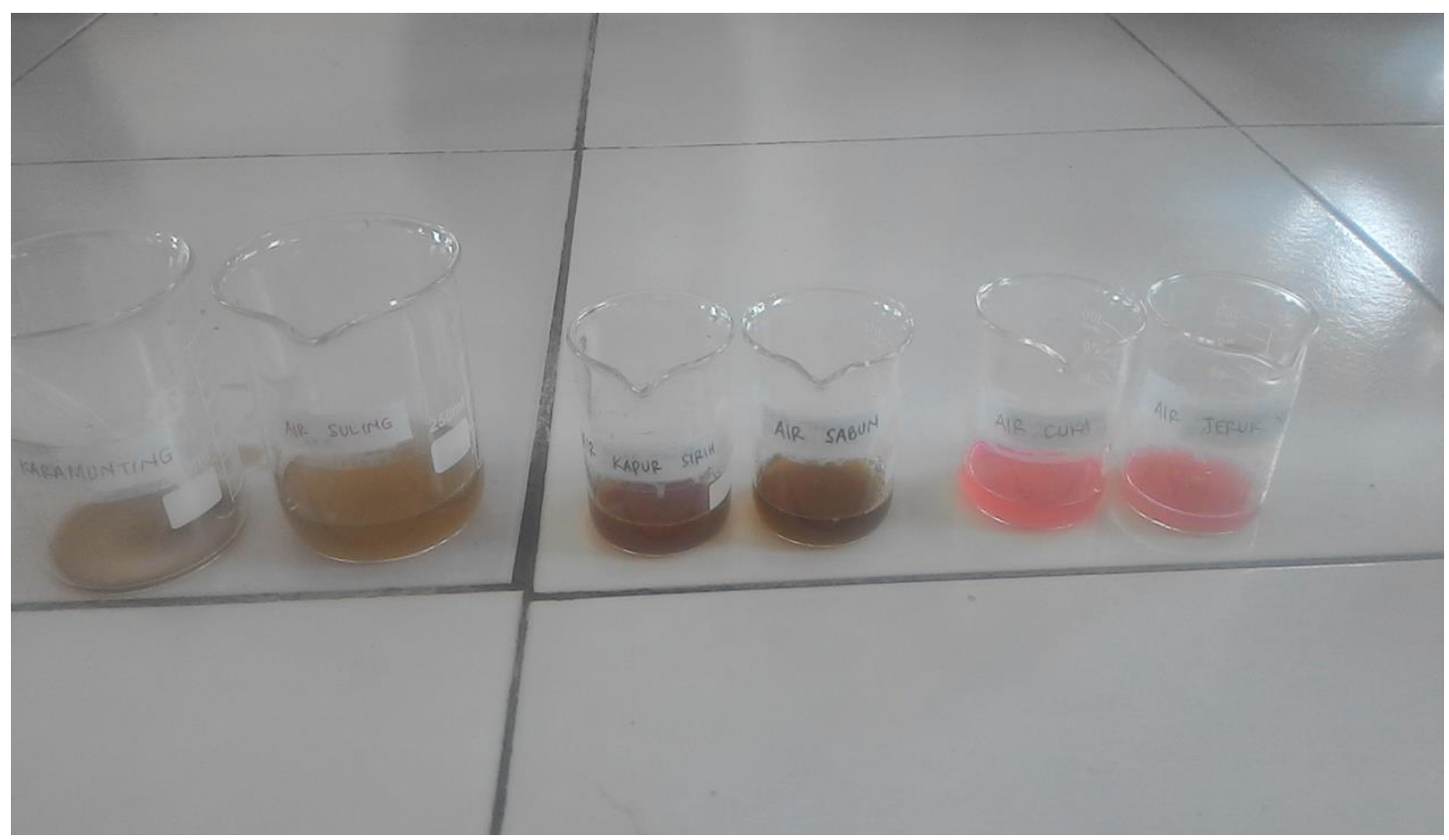

Gambar 6. Setelah di tetesi ekstrak Bunga Karamunting

Dari hasil penelitian (gambar di atas) dapat di lihat perubahan warna yang terjadi pada larutan cuka, air jeruk nipis yang bersifat asam berubah menjadi merah muda. Pada air sabun dan air kapur yang bersifat basa berubah menjadi coklat. 
Indikator alami yaitu indikator yang berasal dari bahan-bahan alami, dimana cara memperolehnya yaitu dengan cara mengekstrak. Prinsip indikator adalah bahan yang memberikan warna berbeda pada zat yang bersifat asam dan basa . Indikator alami yang biasa di pakai adalah dalam pengujian sama basa adalah tumbuhan yang berwarna mencolok berupa bunga-bungaan, umbi-umbian, kulit buah dan dedauanan.

Bunga karamunting dapat dijadikan indikator alami utuk menentukan sifat asam dan basa suatu zat atau senyawa karena memberikan perubahan warna yang jelas pada larutan asam dan basa. Pada larutan asam menjadi merah muda dan pada larutan basa menjadi coklat.

Selain itu suatu tumbuhan dapat menjadi indikator yang baik adalah karena pada kelopak bunga tumbuhan memiliki pigmen sehingga ketika diekstrak menghasilkan berbagai warna. Indikator asam basa yang baik adalah yang dapat memperlihatkan warna berbeda dalam larutan yang bersifat asam dan basa.

Di bawah ini merupakan pigmen-pigmen warna alami yang dapat mendeteksi asam atau basa :

- Alizarin adalah warna oranye yang dapat ditemukan di akar tanaman madder plant; Ianya digunakan untuk mewarnai wol di Mesir Kuno, Persia, dan India. Di larutan alkohol 0,5\% alizarin berwarna kuning pada $\mathrm{pH} 5.5$ dan berwarna merah pada $\mathrm{pH}$ 6.8. Alizarin yang telah dimodifikasi secara sintetis juga dapat digunakan sebagai indikator asam basa.

- Cochineal adalah indikator asam basa yang dibuat dari tubuh serangga cochineal yang dikeringkan, serangga ini dapat ditemukan di Mexico dan Amerika Tengah. Kita hari menggiling sekitar 70.000 serangga untuk membuat 1 pon indikator kering. Bubuknya mengandung sekitar 10\% Asam carminic yang berwarna kuning di larutan asam, dan ungu tua di larutan basa. Larutan Cochineal tidak digunakan sebagai indikator asam basa lagi.

- Curcumin, yaitu kuning kunyit adalah pewarna alami yang ditemukan di bubuk kari. Warna ekstrak kunyit berwarna kuning di $\mathrm{pH} 7.4$ dan berubah menjadi merah di $\mathrm{pH}$ 8.6.

- Esculin adalah pewarna fluorescent yang bisa diekstrak dari daun dan kulit batang pohon berangan kuda. Kita perlu memancarkan sebuah cahaya hitam (ultraviolet) pada indikator ini untuk mendapat efek terbaiknya. Esculin berubah dari tidak berwarna di pH 1.5 menjadi biru fluorescent di pH 2 .

- Anthocyanin adalah indikator asam basa yang paling mudah untuk didapatkan; ini adalah pigmen warna tanaman yang membuat kol ungu berwarna ungu, bunga cornflower berwarna biru, dan bunga poppy berwarna merah. Antocyanin berwarna merah di larutan asam, berubah menjadi keunguan dan hijau di larutan basa lemah dan kuning di larutan basa kuat.

Perhatikan gambar di bawah ini.

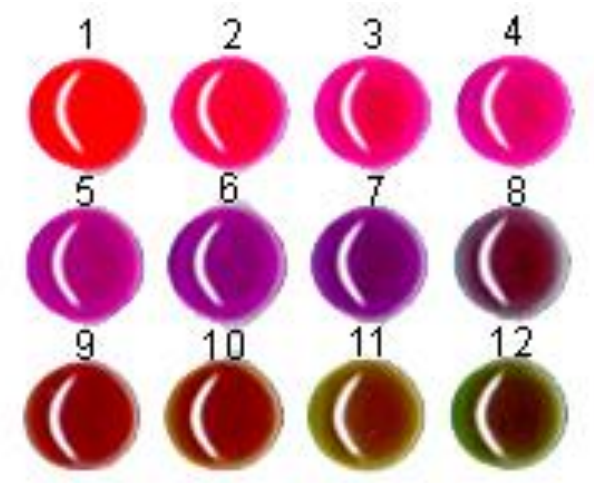


- Litmus adalah pewarna biru yang diekstrak dari berbagai spesies lumut kerah. Walaupun lumut keran ini tumbuh di berbagai daerah di dunia ini, hamper semua litmus diekstrak dan dikemas di Belanda. Litmus berwarna merah di $\mathrm{pH} 4.5$ dan biru di sekitar $\mathrm{pH}$ 8.3. Sebagian besar Litmus digunakan untuk membuat kertas Lakmus, dan dapat juga dipakai sebagai pewarna pada minuman.

- Logwood adalah pewarna yang didapatkan dari bagian inti pohon dari sejenis pohon yang tumbuh di Amerika Tengah dan daerah Hindia Barat. Ekstrak ini berisi hematoxylin dan hematein, yang berubah menjadi merah cerah di larutan basa.

- Betalains adalah kelas "indole-derived pigments" berwarna merah dan kuning yang ditemukan di tanaman berordo Caryophyllales, dimana pigmen ini menggantikan pigmen antocyanin. Betalain juga ditemukan pada spesies jamur tingkat tinggi.

\section{KESIMPULAN}

Dari penelitian yang telah dilakukan, dapat disimpulkan bahwa estrak bunga karamunting dapat dijadikan indikator alami untuk menentukan sifat asam dan basa suatu zat atau senyawa karena memberikan perubahan warna yang jelas pada asam dan basa. Pada larutan asam menjadi merah muda dan pada larutan basa menjadi coklat.

Agar dapat dilakukan penelitian yang lebih dalam lagi mengenai tumbuhan yang dapat di gunakan sebagai indikator alami asam dan basa.

\section{DAFTAR PUSTAKA}

Kimia XI IPA. (2004). Unggul Sudarmo. Jakarta: Erlangga.

Kimia XI IPA. (2006). Michael Purba. Jakarta: Erlangga.

Pembuatan indikator alam alami. (2014). Retrieved from Desktopotato.wordpress.com www.scribd.com. (2015, April).

Bukupedia. (2016, Maret). Retrieved from Bukupedia.

PR Kimia kelas XI. (2016). Tim Penysusn. Jakarta: Intan Pariawara.

Pigmen indikator alami. (2017). Retrieved from mely-phoenix7.aurora.com 